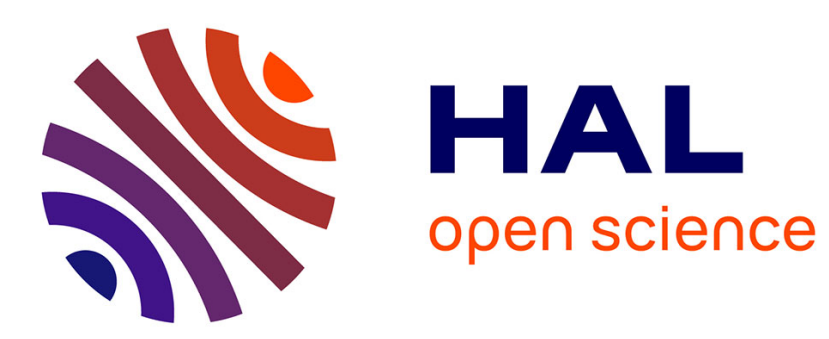

\title{
Time and the structuring of ritual performance in the xenotransplantation debate
}

\author{
Julia Bickford, Charles Mather, Usher Fleising
}

\section{To cite this version:}

Julia Bickford, Charles Mather, Usher Fleising. Time and the structuring of ritual performance in the xenotransplantation debate. Public Understanding of Science, 2005, 14 (3), pp.235-247. 10.1177/0963662505047525. hal-00571051

\section{HAL Id: hal-00571051 \\ https://hal.science/hal-00571051}

Submitted on 1 Mar 2011

HAL is a multi-disciplinary open access archive for the deposit and dissemination of scientific research documents, whether they are published or not. The documents may come from teaching and research institutions in France or abroad, or from public or private research centers.
L'archive ouverte pluridisciplinaire HAL, est destinée au dépôt et à la diffusion de documents scientifiques de niveau recherche, publiés ou non, émanant des établissements d'enseignement et de recherche français ou étrangers, des laboratoires publics ou privés. 


\title{
Time and the structuring of ritual performance in the xenotransplantation debate
}

\author{
Julia Bickford, Charles Mather and Usher Fleising
}

Advancements in biotechnology provoke fundamental questions about the relationship of humans to the natural world. A crisis arises as the knowledge, practice, and policies concerning biotechnology grow further out of step with each other. This paper examines the role of ritual performance as a means of resolving this crisis, uniting the organic with the socio-moral aspects of science, technology and regulatory policy. Ritual performance is evident in the public discussions of the United States' Secretary's Advisory Committee on Xenotransplantation (SACX). In an attempt to understand the cultural responses to new knowledge, this paper examines the transcripts of several SACX meetings for its ritual elements and references to authority. We find that time is used by scientists to structure ritual performance in a way that guides public policy and attitudes toward xenotransplantation.

\section{Introduction}

All the world is not, of course, a stage, but the crucial ways in which it isn't are not easy to specify. (Goffman, 1959: 72)

Xenotransplantation, "transplantation of cells, tissues or organs from non-humans to humans" (Nature Medicine, 2001), is part of a suite of medical therapeutic interventions that have elicited intense debate about the direction and use of biological knowledge. Together with gene therapy, genetic testing, and reproductive manipulation, xenotransplantation exposes the fragile border between the organic and the socio-moral. Edmund Leach (1976) observed that border debates that involve a crossing of boundaries are always hedged about with ritual. These rituals involve time-out behavior and the seeking of guidance from authoritative voices. Contemporary versions of such a ritual are the regulatory arrangements implemented by governments to mediate the relationship between society and the use of biological knowledge.

In the United States the Secretary's Advisory Committee on Xenotransplantation (SACX) is the socially sanctioned body charged with developing policy guidelines and recommendations regarding xenotransplantation (National Institutes of Health, 2001). In the SACX forum definitions of risk and benefit are negotiated. This regulatory and quasi-legal theater is one forum through which (American) society articulates its relationship with nature. It is a social drama (Turner, 1986, 1990) where scientific authority and market 
authority (the center) meets sectarian or border authority (Douglas and Wildavsky, 1982). In this paper we present a content analysis of the proceedings of several meetings of the SACX to demonstrate its ritual structure and the practices invoked to transmit collective messages by authoritative voices. We begin with a brief overview of the social problems associated with xenotransplantation and of the creation of the SACX. ${ }^{1}$

\section{Xenotransplantation: the context}

\section{The social problems of xenotransplantation}

The strong case for xenotransplantation is made in relation to therapeutic advances in human-human organ transplantation. The refining of immunosuppressant agents has resulted in a situation where according to one source in 2000 over 62,000 people in the United States were waiting for donor organs (Genetic Engineering News, 2000: 28).

Xenotransplantation is offered as an adjunct to organ transplantation. The technology offers the possibility of saving patient lives; however, this benefit must be viewed as a tradeoff with the possible societal risk of new diseases entering the human population and the symbolic response of the general public referred to as the "yuk" factor. There are thus two substantive social problems facing xenotransplantation, one is epidemiological and the second is moral/symbolic.

Pigs are often the focus of research in xenotransplantation "because of the similarity of their organs to human organs in size and function" (Genetic Engineering News, 2000: 28). Clinical trials have taken place in Sweden and the United States, including the transplantation of "fetal pig neural cells into patients with Parkinson's disease; fetal pig islet cells transplanted into diabetic patients; and genetically modified pig livers used to temporarily treat patients with severe liver failure" (Health Canada, 2001). Whole organ transplants have yet to be approved.

"Xenotransplants pose a risk to the general public because they may cause new types of infections diseases .. . animal disease agents may be transmitted to humans through transplanted cells, tissues, or organs" (Health Canada, 2001). One of the risks is the transfer to humans of porcine endogenous retrovirus (PERV). Laboratory experiments demonstrate that PERV can infect human cells giving rise to the possibility for a "life-threatening pandemic" (Nature Medicine, 2001) transmitted by those in close contact with a xenotransplant patient. Thus, risk is a serious concern in the public debate surrounding this new technology.

The moral/symbolic transgressions of xenotransplantation have been framed within themes of the body, individuality, patient identity, and what it means to be human. Haraway (1991: 212-13) describes the "late twentieth century biotechnical body": "Bodies have become cyborgs - cybernetic organisms — compounds of hybrid techno-organic embodiment and textuality ... The cyborg is text, machine, body, and metaphor . . .." Ideas of culture, science, sociality and technology cannot be separated in this postmodern view of the human body. In discussing her patients' experiences of xenotransplantation, Lundin (1999) describes "the boundless body." Midgley (2000) more directly addresses the "yuk" factor, the visceral annoyance of placing animal organs in human bodies. Ontological insecurity arises as boundaries of animal/human and nature/culture are transgressed. Midgley (2000: 8) states:

Biotechnology ... a appears not to be compatible with our existing concepts of nature and species-concepts that are part of our current science as well as of everyday 
thought. And a new ideology is being proposed that would remodel those concepts to fit the new technologies, envisaging species as unreal and nature as infinitely malleable.

As patients' bodies are inhabited by parts of someone or something else, the conventional cultural categories for humanness erode. Caught between opportunities and risk, patients struggle to construct clear self-images and interpret what medical technology means for their lives. Images of half-human half-animal chimeras and stories such as Mary Shelley's Frankenstein provoke questions about "how many genes you can change before you are changed as a human being" (Lundin, 1999: 19).

\section{The institutional response to xenotransplantation in the United States}

The Secretary's Advisory Committee on Xenotransplantation (SACX) was created in the United States in July 1999 (National Institutes of Health, 2001). This committee was organized to make recommendations on policy and procedures, considering the scientific, medical, social, and ethical issues related to xenotransplantation. The committee consists of 18 voting members who have expertise in such fields as xenotransplantation, epidemiology, virology, microbiology, infectious diseases, molecular biology, veterinary medicine, immunology, public health, bioethics, social sciences, psychology, patient advocacy, and animal welfare. As well, at least one member must be a current member of the Food and Drug Administration (FDA) and another must be a current member of the Centers for Disease Control and Prevention (CDC). The SACX meetings offer an avenue to investigate the relationship between experts and publics in the United States.

\section{Method}

This article is concerned with understanding how scientists and various experts in attendance at the meetings of the SACX present information on xenotransplantation to the public. The SACX meetings analyzed were held under the auspices of the US Department of Health and Human Services, between February 2001 and March 2002. The committee met on four occasions over a period of 13 months: 20 and 21 February 2001; 2 and 3 July 2001; 29 and 30 November 2001; and 11 and 12 March 2002. Two members of the research team attended the March 2002 meetings in Bethesda, Maryland. A content analysis was performed on transcripts available on the SACX website.

Meetings typically began with opening remarks, followed by various presentations outlining specific issues related to xenotransplantation. A short question and answer period followed each presentation, inviting committee members to ask questions for purposes of clarification. Built into the agenda for the March 2002 meeting was a science break-out session which involved no public participation. Thus, the public was allowed to participate in the SACX meetings only at specific, designated times. Transcripts from the four SACX meetings, as well as from the science break-out sessions were subject to content analysis using the qualitative software program NVIVO. ${ }^{2}$ Research focused on the authorities to which scientists appeal in order to validate xenotransplantation. Science itself, in Western society generally and the United States specifically (Aronowitz, 1988), is an obvious appeal to authority as are references to religion. However, an initial survey of the text indicated that appeals to history are a subtle means of seeking authority for current research and practice. Further analysis placed historical authority within a larger conceptualization of time that includes the present and future. 


\section{SACX as cultural performance and social drama}

While themes of patient identity, the body, and what it means to be human are an important means of highlighting the cultural implications that particular technologies have for society, we set about to view xenotransplantation from the perspective of the scientists, gaining an understanding of how these experts inform the public in a way that intersects with cultural norms and values. Thus, it is not only the patients who grapple with this new technology; the scientists and decision-makers struggle to come to terms with the organic and socio-moral aspects of xenotransplantation; this is revealed in the way they present information to the public and how they talk amongst themselves.

Cultural performance was proposed by Milton Singer and adopted by anthropologists and folklorists to refer to a unit of analysis to circumscribe "Plays, concerts, and lectures ... but also prayers, ritual readings and recitations, rites and ceremonies, festivals, and all those things we usually classify under religion and ritual rather than with the cultural and artistic" (Singer, 1972: 71). This concept of cultural performance is similar to what Victor Turner calls a "social drama" and both Turner and Singer wrote about social dramas and performances and the extension of these into technologically complex societies (Turner, 1990: 8; Singer, 1972: 71).

The idea of social drama, described by Victor Turner (1979) involves a breach of the norm causing a crisis. Turner (1986) describes crisis as a period when knowledge, practice, and policy are out of step. The new biotechnologies have initiated several such breaches which press on the legal conversion of ethical norms. Property right claims on living organisms, the release of genetically modified products into the environment, the use of fetal tissue, cloning, and xenotransplantation are representative cases where life-science knowledge demands social policy decision.

Ritual performance is a cultural means of managing the conflicts of crisis and the emotional baggage associated with social change, invention, and challenge in biotechnology; ritual performance allows a "thing" to simultaneously belong in the socio-moral and the organic realms. This crisis leads to redressive action and finally reintegration or the legitimating of an irreparable schism. The value of this partition is that it is a way of organizing symbolic data. Because symbols are emotive, the analysis heightens the awareness of the undercurrents that drive the passions of the performance. As Turner phrases it, there is an effort in such symbolic expression to unite the organic with the sociomoral order. According to Turner's sequence, the SACX meetings are a means of redressive action, attempting to resolve the breach of norms, a means of bringing the strange into the realm of the familiar.

\section{Control and authentic identity}

Performance is dramaturgical and involves the ways in which an individual "guides and controls the impression [others] form of him, and the kinds of things he may and may not do while sustaining his performance before them" (Goffman, 1959: xi). Everyday life, as Goffman proposes, and all social interactions require a kind of performance. Humans attempt to control the definition of a situation and the impression of the audience through behavior or actions.

When before an audience, people tend to highlight assenting facts in order to control the audience's impression. Thus, performances are often idealized. According to Goffman (1959: 35): 
When the individual presents himself before others, his performance will tend to incorporate and exemplify the officially accredited values of the society, more so, in fact, than does his behavior as a whole ... performance highlights the common official values of the society in which it occurs . . . as an expressive rejuvenation and reaffirmation of the moral values of the community.

Since the performer attempts to maintain an idealized definition of the situation, facts that are conflicting with such a definition are generally under-communicated.

As described in Goffman's (1959) chapter on "The Arts of Impression Management," it is important to control the access an audience has to front regions and back regions of the performance in order to regulate information. Failure to do so involves ritual contamination of the performer and may result in a loss of control in defining the situation. An analogous situation to front and back regions of performance is found within the common layout of a house. For example, a more formal living room is typically located at the front of one's house while the kitchen is positioned at the rear. One's access to the kitchen depends on one's intimacy with the household. The formal impression of the living room would be disrupted if a visitor were to stray into the kitchen.

Performance has many functions, as outlined by Schechner (2002). The intended functions of the SACX performance, according to Schechner, could involve marking or changing identity, teaching, persuading, convincing, fostering community, and dealing with the sacred and/or demonic. Schechner (1985: 4) comments that humans, unique among animals, "carry and express multiple and ambivalent identities simultaneously."

Rituals help people to "deal with difficult transitions, ambivalent relationships, hierarchies, and desires that trouble, exceed, or violate the norms of daily life" (Schechner, 2002: 45). They occur in special places requiring particular behavior. The SACX meetings are an example of ritual actions that temporarily change a space from ordinary to special. The specific people meeting in the area and the purpose of the SACX meetings transformed the hotel conference room into a federal space. Located in Bethesda, Maryland, a short distance from Washington DC, the wider geographical position of the conference is a special place. Particular people perform specific jobs in a nation's capital. The capital becomes the formal living room when mapped on to the analogy of the house. It is where important foreign dignitaries are received. Moreover, this location is sacred as it conjures strong emotions associated with American ideology of freedom, liberty, and justice.

What transformed the space of the hotel conference room were the people who conducted business within its walls. Only certain people, those consecrated as members of the advisory panel, are qualified to give a specific performance. Schechner (2002: 5) offers the example of the Mexican dance company that imitated the Yaqui deer dance performance. A Yaqui man from Arizona argued, "You have to be Yaqui, or at least Indian, to understand how the mysteries of that song-the words, the purpose of it . . .." Thus, the Mexican performance was invalid and inauthentic. In order to qualify as authentic performers each SACX panelist was required to take an oath, raising his or her right hand, and swearing to tell the truth:

I note that each of you has already signed this oath as part of a considerable paperwork that came along with membership on a federal advisory committee. Nevertheless, I think that it is appropriate and fitting to say the words aloud. I think they will remind us of the responsibilities that you accept as special government employees. Will the members of the Secretary's Advisory Committee on Xenotransplantation please rise. I would like for you to raise your right hands and repeat the oath after me. I-state your full name - do solemnly swear or affirm that: I will support and defend the Constitution 
of the United States against all enemies, foreign and domestic; That I will bear true faith and allegiance to the same; That I take this obligation freely, without any mental reservation or purpose of evasion; That I will well and faithfully execute the duties of the office on which I am about to enter, so help me, God. (1st meeting, 20 February 2001)

Effectively through this ritual process, the panelists, a wide variety of American citizens, were converted into federal employees, representatives of the government. Thus, ritual involves creativity and makes possible "new situations, identities and social realities" (Schechner, 2002: 57). Further appeals to legitimacy included religious petitions. One member identified himself and his fellow SACX panelists as follows:

... The bodies of complex federal policies that are either in place or in the process of becoming adopted or to use a term in religious history becoming canonical. Now, the word "canonical" brings to mind a comment that I whispered to Robyn Shapiro . . . Robyn; we are like the leaders of Jews, Christians and Muslims. To be a leader this Committee has to work with and master a virtual Bible or Qu'ran filled with authoritative documents, all of which confine and direct what we will be doing. We have to know our canon, and our canon was presented only in brief summary to us yesterday in the form of legislation .... (21 February 2001)

Thus, the ritual behavior of swearing an oath, the religious symbolism of legislation and the constitution, are powerful agents in transforming and shaping the identity of panelists. Through ritual behavior they become valid and legitimate performers, their knowledge authenticated in the eyes of the public. As well, through ritual performance, the ordinary space of the hotel conference room was temporarily altered: "We are supposed to be adjourned by 4:40. By the way, be sure not to leave anything here. Who knows, this may become a dance studio between now and the time we meet in the morning. So, be sure to take everything with you ..." (1st meeting, 20 February 2001).

\section{Time and the validation of authority}

There is a moral bond between members of a community, as certain people hold particular knowledge that others may need (Shapin, 1994). While direct experience may be regarded as the source of factual knowledge, "the overwhelming proportion of our factual beliefs continue to be held at second hand through trusting others" (Shapin, 1994: 25). But who has the right to speak for others? Shapin provides a historical overview of truth, explaining that the identity of the truth-teller is important to the judgments of knowledge claims. He offers the example of Robert Boyle, a member of the seventeenth-century gentry, whose social position deemed him a "transparent spokesperson for reality" (Shapin, 1994: 192). In modern society, however, the nature of trust has shifted from face-to-face familiarity to knowledge that is guaranteed through experts and vouched for by institutions. Scientific knowledge is made and evaluated in private places; however, institutions present a human face to the public at certain "access points."

How is this authentication prosecuted in the SACX meetings? Scientists, who are trusted experts, deliver presentations; knowledge is authenticated by the insignia of their affiliated institution which is tattooed on every power point. The SACX meetings are an "access point," in which a certain perspective of scientific work is offered to the public. In examining the stories the scientists tell-to the public and to each other-we found that time is used in a symbolic way to validate collective meaning. The concept of time plays a significant role in the transfer of knowledge on xenotransplantation. Analysis of transcripts 
reveals that science researchers and practitioners divide time into three categories (distant past, recent past, and future). Each category helps validate practices and values in the present. Ultimately time is depicted as a dialectic between the socio-moral order (originating in the distant past) and the organic foundation (rooted in the recent past) of xenotransplantation which are resolved or synthesized by reference to the future.

References to the distant past stress that xenotransplantation is not a new phenomenon. This provides socio-moral validation for xenotransplantation in the present by making it appear familiar, time-tested, and hence non-threatening to the general public. For example, one panelist highlights the distant past when he said, “. . . the first xenograft, as far as we know, was attempted in about 1906; so we have nearly 100 years of experience in knowing what happens when an organ is xenografted. We know a great deal about it" (4th meeting, 11 March 2002). This speaker alludes to a lengthy history of experience in xenografting as well as assuring the public that "we" (the experts) know a great deal about it, in an attempt to alleviate public apprehension. This appeal to the distant past is repeated by many different members and in different meetings of the SACX. For example, another panel member said "As many of the members of this committee know much better than I, interest in xenotransplantation goes back a long time, at least to the 19th century and arguably before" (1st meeting, 20 February 2001). The socio-moral is evoked again, by conjuring images of the distant past in conjunction with descriptions of war: "In the First World War, I am told that they took sheep into battle with them to act as donors of blood for some of the soldiers" (1st meeting, 20 February 2001). Thus, xenotransplantation is viewed as a heroic activity, saving the lives of injured soldiers. Another speaker referenced the distant past by saying, "So the idea is very old. In fact, back in the 18th century, they started doing blood transfusions from animals to humans, not very satisfactorily and not very successfully, but they did this" (1st meeting, 20 February 2001). Finally, the distant past surfaces again in reference to the rewards (i.e. the Nobel Prize) given to those who study xenotransplantation:

Now, back in 1912, Alexis Carrel here, a Frenchman who was working in New York and actually won the Nobel Prize for medicine for his contributions to vascular surgery, he was the first person who could really join up blood vessels satisfactorily ... . So, he was the first person who really did a lot of organ transplants in experimental animals ... So, here is somebody almost 100 years ago getting it spot on right for what we are trying to do now, which is quite remarkable. It is no wonder he won a Nobel Prize. (1st meeting, 20 February 2001)

Thus, references to the distant past provide socio-moral validation for present scientific work in the area of xenotransplantation. The audience is told that xenotransplantation is timetested, in an attempt to reduce anxiety about the possible risks involved in this technology.

When they discuss the recent past, panel speakers stress the rapid advancements in research. References to the recent past provide validation for the theories and methods of scientists working on xenotransplantation in the present, by stressing the technological advancements and progress in science. For example, one speaker highlights progress in the technology associated with xenotransplantation through the juxtaposition of recent past and present time, "I think that no one 20 years ago would have thought that we would have gotten a primate to 75 days . . no one who was involved would have thought we would have gotten that far. So I think there is a lot of progress" (4th meeting, 11 March 2002). Another example of speakers using the recent past to emphasize current technological advancements was offered in the following quote: "Now we have other tools that were not 
available 35 years ago" (4th meeting, 11 March 2002). A speaker in the first meeting referenced technological advancements in the recent past, saying:

There is another impetus for the recent emphasis on xenotransplantation. As you will hear in more detail later, recent advances in immunology, in molecular biology and bioengineering have made important strides in overcoming the formidable immunological barriers to the survival of animal transplants in humans. These advances include potent immunosuppressant drugs, genetic engineering techniques, and new biomaterials for encapsulating xenotransplantation products. (21 February 2001)

Repeatedly, throughout the SACX meetings, speakers allude to the vast improvements in technology in the recent past. For example, another speaker exclaimed:

There has been extraordinary achievement over the course of the past decade in the field of xenotransplantation; first, the understanding of the pathophysiology of hyperacute rejection in xenogeneic combinations and second, the development of molecular approaches to overcome these problems ... there has been an incredible step forward in the field and fueled much of the optimism from, say, five years ago, that clinical xenotransplantation was just around the corner. (1st meeting, 21 February 2001)

In references to the future, speakers recognize uncertainty and risk as well as scientific progress and the possibility of helping patients. References to the future validate the sociomoral and scientific foundations of present theory and practice in xenotransplantation by emphasizing potential benefits in the form of increased well-being and health for the general public over the potential risks. One speaker refers to xenotransplantation as a future miracle in his quote:

In the last century to put a human on the moon and successful development of allotransplant were considered a miracle. In this century if the pig organ can be transplanted into the human to save the human life, this will be considered another miracle in human history. This is the reason why we are here. (4th meeting, 11 March 2002)

The socio-moral is evoked by the speaker's use of the word "miracle" and in the metaphor of saving human life; simultaneously, the audience is encouraged to accept that the scientific progress involved in xenotransplantation is akin to the historical event of humans going to the moon. Scientific adventure is wrapped into moral arguments for saving human life through xenotransplantation in the speaker's message of future progress. Similarly, the wide application of xenotransplantation in the future provides socio-moral validation for the research: "Well, when will xenotransplantation enter the clinical arena? It's in the clinical arena. As your question implied, there are experimental xenografts of various sorts being carried out . . . As I see it in the future, xenotransplantation will be part of a number of modalities that can potentially be applied" (4th meeting, 11 March 2002). Another speaker echoed this enthusiasm for future applications of xenotransplantation, "The potential clinical application of xenotransplantation includes severe, life-threatening illness such as liver failure, chronic diseases that affect large segments of Americans, including diabetes, and certainly neurological disorders, such as Parkinson's disease" (1st meeting, 20 February 2001). In the second SACX meeting, a panel speaker addressed the future, saying:

I think you put your finger on it. We are talking about potential, potential in two areas, potential of the risk of transmission of disease-we don't know whether that is actually going to occur-and the potential for benefit in terms of alleviating pain and suffering and improving the lives of patients. (2nd meeting, 2 July 2001) 
Thus, appeals to the future are a means of synthesizing the socio-moral and technological warrants for continued work in xenotransplantation, emphasizing the potential benefits over the potential risks.

The SACX panelists referenced all three categories of time when speaking to a public audience. However, the distant past was not discussed in the context of the science break-out session. Scientists do not refer to the distant past when they present information to their peers during science break-out sessions because they already share the same values and a tacit acceptance of the moral validity for doing xenotransplantation. As Schechner (1985: 16) explains, "changes in the audience lead to changes in the performances." Speakers appeal to various categories of time in an attempt to unite the organic with the socio-moral order.

The essential principles that underlie culture are expressed in conceptualizations of time and space, and in public rituals. Ritual is part of the symbology of power characterized by the authority of science over xenotransplantation. This authority also supersedes market authority. As part of a study of the culture of finance in biotechnology one of us (Fleising) attended a series of investment bank sponsored conferences promoting life-science companies. These select gatherings in New York City (five conferences between September 2001 and October 2002) attracted presentations from over 600 companies from the United States and abroad. Not a single company presented xenotransplantation as a focus of their business plan and only two could be identified as having an active interest in xenotransplantation. When bankers and biotechnology analysts were asked about investment interest in xenotransplantation, the response was that there simply was no interest. There was interest in regenerative medicine and stem cell research as the future for organ replacement but xenotransplantation was dismissed as too risky both as a science and as a business. The common comment was that the principal agents proclaiming for xenotransplantation were scientists.

\section{The organic and the socio-moral}

The SACX meetings were a cultural performance, a social and ritual drama, symbolically rich in expressing cultural meanings through which the socio-moral order of the public was united with scientific interests. Scientists have the authority to alter public perceptions of xenotransplantation by placing it within the socio-moral order evoked by references to the distant past. This reconciliation between the socio-moral and organic is essential for continued work in xenotransplantation.

Contradiction is ubiquitous in biotechnology. Fleising (2000), while researching investment bankers, heard one chief executive officer describe biotechnology as being about "genetics, genesis, genitals, and money!" This ambiguous statement combines both the sacred and the profane; it is "an unnatural arrangement, bringing together what sentiment might wish to keep apart" (Fleising, 2000: 232). Likewise, the ambiguous and contradictory natures of socio-moral and organic aspects of xenotransplantation are brought together through ritual performance. Xenotransplantation presents a violation of essential categories, human/animal. But the nature of science involved in xenotransplantation also rests on conflicting messages. Stories revealing the antiquity of xenotransplantation are juxtaposed with narratives that describe the novelty and modernity of this new technology. The public is told at once that xenotransplantation is both old and new.

Following Milton Singer's lead, it is the combination of tradition and change that are celebrated in the ritualized conceptualizations of time at the SACX meetings. These meetings constitute a redressive action; it is simultaneously an affirmation of heritage and 
tradition as well as a signal for social change. While the science may be radical the system remains conservative and traditional. For example, advisory committees are viewed as part of this traditional system and were described by one speaker in the following manner:

... One of the major advisory committees in history was during 1794 during the Whiskey Rebellion, when President George Washington convened a group to give advice and recommendation. Since that time, advisory committees have become very, very popular within the executive branch of the Federal Government. In fact, right now we have about 1,000 advisory committee members across the government doing a number of impressive things, like your committee will be doing. (1st meeting, 20 February 2001)

The celebration is a celebration of change and continuity. Progress is good and science is good; new knowledge is essential to the ideology of progress:

The increase of knowledge and rational control are fundamental values in the creed. They imply a constant dissatisfaction with the existing state of affairs and a willingness to take calculated risks and trying something new. A good society is progressive. (Sutton et al., 1962: 259)

Yet the progress occurs within a familiar governing structure.

\section{Avoiding breaches in ritual performance through restricted "public" participation}

Much effort is exerted in order to maintain smooth and uncontested ritual drama in the SACX performance. Breaches, or instances when the performance does not "come off" as planned, are avoided by restricting where and when public participation is sought; moreover, a highly specialized "public" is recruited, so as to minimize potential violations to the ritual performance. During the time of the SACX meetings, legal action was mounted against the Department of Health and Human Services regarding the selection of SACX committee members. At no time in the transcribed proceedings was this legal battle discussed nor did the legal proceedings impede or halt the continuation of the SACX meeting schedule. One of us (Fleising) interviewed a member of the Campaign for Responsible Transplantation (CRT). Her group had nominated several people to serve on the SACX, during the $1999 / 2000$ call for committee nominations. She said that the CRT is suing the FDA over the selection process and demanding to know the criteria for selection, as none of the people whom the CRT nominated were chosen for the SACX panel. During this interview, this CRT member claimed that the chair of the SACX meetings "is pro-xeno." In addition, she said that, "public participation is non-existent" (17 January 2002). "While convenient for the business traveler, this location is not consumer friendly" (17 January 2002).

The first meeting (February 2001) took place in a hotel situated off a busy highway in Columbia, Maryland, which made the site difficult for some people in the public to access. The meetings were held from 8:00 am to 5:00 pm on weekdays, an inconvenient time for many people who work during the day. A wider public may have been informed about the SACX had the meetings been advertised in widely read newspapers or other popular media; however, the announcements for SACX meetings were only posted on the government website. Moreover, members of the public had to forward their comments ahead of time: "The meeting will be open to the public; however, seating is limited and pre-registration is encouraged . . . there will also be a limited period of time provided for public comment" (Department of Health and Human Services meeting notice). Thus, the demand for preregistration of public comments inhibited opportunity for spontaneous involvement or public 
comment in response to SACX speaker presentations. For example, one speaker from the public said, "I was told I had five minutes, but really this presentation takes ten and I really wanted half and hour ..." (2nd SACX meeting, 2 July 2001). This woman was not given the time she needed to voice her comments. "In addition to that I made a printout at the front of each of the workshop copies; I made a printout going into a little more detail about the 11 points because I won't have time to really be going into much detail today" (2 July 2001). This woman, who was given five minutes to deliver all of her 11 pre-registered comments, was in fact the only member of the public to speak during this entire two-day meeting.

Moreover, her status as a member of the "public" is questionable; she introduced herself by describing her employment, "I am from Health Canada, the Center for Infectious Disease Prevention and Control, and I have actually worked on the regulatory side of xenotransplantation in Canada" (2 July 2001). Clearly this member of the public is a highly specialized expert, familiar with the science and policy involved in xenotransplantation; thus, the public who participated in the SACX meetings were not representative of most American citizens. As well, some of the meetings, science break-out sessions, were not open to public participation; pubic participation was severely restricted. To what degree can the SACX proceedings claim to have public participation? Was the public being represented at these meetings?

\section{Conclusion}

Xenotransplantation offers the possibility of mitigating the paucity of donor organs, but at what cost? What are the risks and how does this affect the relationship between humans and nature? Leon Kass (1985) asks about the direction of research and the use of biological knowledge as well as the relationship between scientific knowledge and definitions of what is good for humans. "A full understanding of the new technology of man requires an exploration of ends, values, standards. What ends will or should the new techniques serve? What values should guide society's adjustments? . . Behind these questions lie others: what is a good man, what is a good life for man, what is a good community?" In essence, technology is both a technical and social system, one that shapes society as much as it is shaped, in turn, by society (Bijker and Law, 1992; Bijker et al., 1993). An investigation of xenotransplantation reveals the ambiguity between socio-moral values and organic technology.

The SACX meetings provide an "inter-subjective articulation of experience, which has a beginning and an ending and thus becomes transformed into an expression" (Bruner and Turner, 1986: 6). The expression that is the SACX meetings is a story told. The stories at SACX meetings are tellings and retellings of the history and future of xenotransplantation. There is a liturgy; temporal categories provide order, a sequence, for contexts. Authoritative voices are summoned for these ceremonies, as are incantations from leaders. These incantations are about science, health and morals.

The experience is structured "in milieus detached from mundane life" (Turner, 1986: 41) that affirm a moral-legal cosmology for the proper pursuit of a scientific advancement. The performance drama captures the ethos of xenotransplantation.

Scientific advancements in xenotransplantation often raise questions about ethics and morality. The topic is fraught with ambiguity and contradiction as SACX speakers describe this technology as simultaneously a long-tested phenomenon of the distant past and a new possibility of cutting-edge science. Appeals to both the socio-moral (ideas of benevolent behavior, progress) and the organic (the physical capability of xenotransplantation) validated 
present research. Thus, speakers described xenotransplantation according to specific categories of time, creating a story and thereby providing an ending which takes place in the future. References to the distant past were common in the public discussions and placed xenotransplantation within the socio-moral order. However, a lack of such references during science break-out sessions suggests that socio-moral validation is tacit and taken for granted among scientists.

\section{Acknowledgements}

This project was funded by the Social Sciences and Humanities Research Council of Canada (SSHRC), "Animal Organs for Human Transplant: Public Verdicts, Policy Outcomes." The principal investigator is Edna Einsiedel, University of Calgary, and Usher Fleising is coinvestigator. We would like to thank Liam Taylor for his contributions to this project. We would also like to thank the anonymous reviewers for their valuable comments.

\section{Notes}

1 This project is part of a larger international study titled "Animal Organs for Human Transplant: Public Verdicts, Policy Outcomes." This larger project examined the role of publics in decision-making concerning biotechnology and concentrated on Sweden, Switzerland, the Netherlands, the United Kingdom, and the United States.

2 NVIVO coding facilitated "thinking-up" from the data; it provided an interpretive, analytic process for filtering information in different ways. By coding anything related to authority "time" repeatedly jumped out of the data. While this coding could also have been done using colored pencils and paper, NVIVO allows an efficient means for organizing nodes. For example all related quotes to the distant past could be collapsed into one location. Then it was a simple matter to see if all the subcategories of time were present in each of the four meetings.

\section{References}

Aronowitz, S. (1988) Science as Power: Discourse and Ideology in Modern Society. Minneapolis: University of Minneapolis Press.

Bijker, W. and Law, J. (1992) Shaping Technology/Building Society: Studies in Sociotechnical Change. Cambridge, MA: MIT Press.

Bijker, W., Hughes, T. and Pinch, T. (1993) The Social Construction of Technological Systems: New Directions in the Sociology and History of Technology. Cambridge, MA: MIT Press.

Bruner, E.M. and Turner, V. (1986) The Anthropology of Experience. Urbana: University of Illinois Press.

Douglas, M. and Wildavsky, A.B. (1982) Risk and Culture. Berkeley: University of California Press.

Fleising, U. (2000) "The Ethology of Mythical Images in Healthcare Biotechnology: A Methodological Approach to Uncovering Ritualized Behavior in the Evolution of Sickness and Healing," Anthropology and Medicine 7: $227-49$.

Genetic Engineering News (2000) "Strides in Xenotransplantation: The Challenge of Overcoming Hyperacute Rejection Examined at BIO 2000 in Boston," Genetic Engineering News 20(8): 1, 28 and 73.

Goffman, E. (1959) Presentation of Self in Everyday Life. New York: Doubleday Anchor Books.

Haraway, D.J. (1991) Simians, Cyborgs, and Women: The Reinvention of Nature. New York: Routledge.

Health Canada (2001) "Xenotransplantation" [online]. Available: http://www.hc-sc.gc.ca/hpb-dgps/therapeut/zfiles/ english/fact-sht/fact_xeno_e.html.

Kass, L. (1985) Toward a More Natural Science: Biology and Human Affairs. New York: The Free Press.

Leach, E. (1976) Culture and Communication: The Logic by Which Symbols Are Connected. Cambridge: Cambridge University Press.

Lundin, S. (1999) “The Boundless Body: Cultural Perspectives on Xenotransplantation," Ethnos 64: 5-31.

Midgley, M. (2000) "Biotechnology and Monstrosity: Why We Should Pay Attention to the 'Yuk Factor," The Hastings Center Report 30: 7-15.

National Institutes of Health (2001) "Office of Biotechnology Activities: About the SACX" [online]. Available: http://www4.od.nih.gov/oba/sacx/aboutsacx.htm.

Nature Medicine (2001) "Focus on Xenotransplantation: The Promise and Problems of Xenotransplantation" [online]. Available: http://www.nature.com/nm/web_specials/xeno/. 
Schechner, R. (1985) Between Theatre and Anthropology. Philadelphia: University of Pennsylvania Press.

Schechner, R. (2002) Performance Studies: An Introduction. New York: Routledge.

Shapin, S. (1994) A Social History of Truth: Civility and Science in Seventeenth Century England. Chicago: University of Chicago Press.

Singer, M. (1972) When a Great Tradition Modernizes: An Anthropological Approach to Indian Civilization. New York: Praeger.

Sutton, F.X., Harris, S.E., Kaysen, C. and Tobin, J. (1962) The American Business Creed. New York: Schocken Books.

Turner, V. (1979) Process, Performance, and Pilgrimage: A Study in Comparative Symbology. New Delhi: Concept.

Turner, V. (1986) The Anthropology of Performance. New York: PAJ Publications.

Turner, V. (1990) Dramas, Fields, and Metaphors: Symbolic Action in Human Society. Ithaca, NY: Cornell University Press.

\section{Authors}

Julia Bickford is a research associate in the Department of Family Medicine at the University of Calgary. Charles Mather is an Assistant Professor in the Department of Anthropology at the University of Calgary. Usher Fleising is Emeritus Professor in the Department of Anthropology at the University of Calgary. Correspondence: Julia Bickford, Department of Family Medicine, University of Calgary, 1635-14th Avenue NW, Calgary, AB, T2N 1M7 Canada; e-mail: jjbickfo@ucalgary.ca 